Cadernos Walter Benjamin 21

\title{
CONSTELAÇÕES DE FRAGMENTOS METODOLÓGICOS E HISTÓRICOS EM BENJAMIN
}

Cristiane Maria Marinho

\begin{abstract}
RESUMO
O objetivo deste artigo é mostrar a permanência de alguns conceitos presentes no Prólogo epistemológico-crítico, do livro Origem do drama trágico alemão (1924), de Walter Benjamin, no texto Sobre o conceito da História (1940). Ao falarmos em permanência desses conceitos estamos nos referindo à uma permanência ampliada, no sentido de serem retomados em contextos diferentes, mas sem rupturas radicais nos elos dessas obras, pois apesar da construção fragmentária da obra benjaminiana, é possível afirmar uma totalidade constelar. A estrutura do artigo está assim divida: 1 - Fragmentos conceituais do Prólogo epistemológico-crítico do livro Origem do drama trágico alemão, composto da exposição exegética das principais categorias do prefácio do referido livro; 2 - Metodologia e Política: um mosaico de História e Conhecimento, nesse item são as categorias analisadas no primeiro item dentro do corpo do texto das teses sobre o conceito de História, buscando seus contornos metodológicos e políticos.
\end{abstract}

Palavras-chave: Apresentação (Darstellung). Drama barroco. História. Metodologia. Política

\section{ABSTRACT \\ CONSTELLATIONS OF METHODOLOGICAL AND HISTORICAL FRAGMENTS IN WALTER BENJAMIN}

The objective of this paper is to show the permanence of some concepts that are contained in the Epistemo - Critical Prologue of the book" Origem do drama trágico alemão" ,1924 (The Origin of German Tragic Drama ) by Walter Benjamim, in the text "Sobre o conceito da história", 1940 ( On History Concept ).When speaking about these concepts of permanence we refer to a kind of extended permanence in the sense of being resumed in different contexts, but without radical disruptions in the links of these works. Despite a fragmented construction in Benjaminian work, it is possible to accept that it is a constelar totality.The structure of this paper is organized as follows: 1-Conceptual fragments of the epistemo-critical Prologue in the book "The Origin of German Tragic drama",comprised of an exegetical presentation of the main categories of the preface of the above-mentioned book;2- Methodology and Politics: A patchwork of History and Knowledge. In this part , the categories are analyzed in

\footnotetext{
Professora Associada de Filosofia e Professora Permanente do Mestrado Acadêmico em Serviço Social - Universidade Estadual do Ceará (UECE); doutoranda em Filosofia Universidade Federal de Goiás (UFG). Brasileira, residente em Fortaleza-CE. Email: 
the first item inside the body of the text of the theses about the concept of History by pursuing its methodological and political contours.

Keywords: Presentation (Darstellung). Baroque drama. History. Politics.

\section{Introdução}

O objetivo deste artigo é mostrar a permanência de alguns conceitos já presentes no Prólogo epistemológico-crítico, do livro Origem do drama trágico alemão (1924), de Walter Benjamin, no texto Sobre o conceito da História (1940). Quando se fala aqui em permanência é no sentido de uma permanência ampliada, pois se compreende que não há rupturas radicais na produção filosófica desse autor, apesar do caráter descontínuo e assistemático de sua obra. Prefere-se falar em construção fragmentária, uma obra em forma de mosaico que com seus fragmentos constitui uma totalidade constelar. A análise feita aqui é importante sob esse aspecto porque são duas obras que tem especificidades singulares e pertencem a momentos bem distintos de sua vida, tanto no que diz respeito à sua vida quanto aos desdobramentos conceituais de sua filosofia, mas que se encontram nos seus respectivos extremos que se singularizam e se tocam.

Quanto aos textos. No que diz respeito ao primeiro, seguimos aqui as traduções, em língua portuguesa, de João Barrento, Origem do drama trágico alemã (2011), e de Sergio Paulo Rouanet, Origem do drama barroco alemão (1984), que apesar de terem traduções diferentes nos títulos, padecem do mesmo problema de tradução quanto à palavra alemã Darstellung traduzida como representação. Aqui foi dada preferência pelo termo correspondente mais adequado de apresentação, conforme polêmicas e revisões recentes (Gagnebin, 2005; Damião, 2006; Cantinho, 2015; Callado, 2006;). Haja vista que, conforme Gagnebin (2005), representação estaria mais próximo de uma filosofia tradicional baseada na relação mental de objetos exteriores ao sujeito, da qual Benjamin critica e se distancia.

\footnotetext{
Professora Associada de Filosofia e Professora Permanente do Mestrado Acadêmico em Serviço Social - Universidade Estadual do Ceará (UECE); doutoranda em Filosofia Universidade Federal de Goiás (UFG). Brasileira, residente em Fortaleza-CE. Email: 
Quanto ao segundo texto, utilizamos três traduções, todas com o mesmo título, Sobre o conceito da História: Sérgio Paulo Rouanet (1994); João Barrento (2008); Jeanne Marie Gagnebin e Marcos Lutz Müller (2005). No entanto, usamos essa última para as citações e compilações. Ainda com relação ao título desse texto, lembramos aqui que, conforme Barrento (2008, 147), nos comentários ao livro Walter Benjamin: o anjo da História, o único título que pode ser considerado autorizado por Benjamin é Sobre o conceito da História, "utilizado nas primeiras impressões do texto, no número especial da Revista de Investigação Social de Horkheimer e Adorno (Em memória de Walter Benjamin), em 1942, e na revista Neue Rundschau [...]". Barrento informa ainda que o título pelo qual o texto ficou mais conhecido, Teses sobre a filosofia da história, nunca foi utilizado pelo autor, tendo aparecido assim em 1955 em uma edição das Obras (Schriften) de Benjamin, organizada por Adorno.

A estrutura neste artigo se divide em duas partes: 1 - Fragmentos conceituais do Prólogo epistemológico-crítico do livro Origem do drama trágico alemão; 2 - Metodologia e Política: um mosaico de História e Conhecimento. O primeiro item buscará expor as principais categorias do prefácio do referido livro de Benjamin em um estilo mais exegético de análise do texto. Essa exposição é importante para referendar o segundo item que retoma essas categorias e as reconhece no corpo das teses sobre o conceito de História. Esse reconhecimento é realizado em dois movimentos: metodológico e político.

\section{Fragmentos conceituais do Prólogo epistemológico-crítico do livro Origem do drama trágico alemão}

Benjamin inicia o seu Prólogo epistemológico-crítico propondo um novo método filosófico, o da apresentação, e o confronta criticamente com a filosofia tradicional por esta ser uma doutrina acabada, ter um caráter fechado e optar por um método more geométrico. Contudo, para Benjamin não há plausibilidade nessa proposta, pois a doutrina filosófica não pode ter esse 
caráter meramente dedutivo. Assim, defende uma "alternativa da forma filosófica, colocada pelos conceitos da doutrina e do ensaio esotérico" (BENJAMIN, 2011, 16), alertando para os riscos que uma filosofia fechada, dedutiva e sistemática pode trazer: um sincretismo que captura a verdade fora do objeto e um universalismo abstrato.

A filosofia não deve ser um mero guia de conhecimento que organiza a verdade de forma a priori em um sistema, mas deve manter sua forma própria que é a de apresentar a verdade em seu movimento imprevisível e não intencional. E a melhor maneira de praticar essa apresentação, segundo Benjamin, é "sob a forma propedêutica que pode ser designada pelo termo escolástico do 'tratado', porque ele reenvia, ainda que apenas de forma latente, para os objetos da teologia, sem os quais não é possível pensar a verdade" (Ibidem). O tratado não é autoritário, pois seu rigor didático emerge da própria autoridade da doutrina e não coage por meio da demonstração matemática dedutiva. $O$ não autoritarismo e a não linearidade do tratado se traduzem no fato da apresentação ser a essência do seu método, compreendido como caminho indireto, desvio: "A apresentação como desvio é, portanto, a característica metodológica do tratado" (BENJAMIN, 1984, 50). Ou seja, o objetivo epistemológico não é o desvelamento linear e objetivo do objeto a ser conhecido, tal como na tradição da filosofia representativa.

Ao contrário, há uma renúncia ao percurso ininterrupto da intenção, pois no tratado a apresentação, tem "o pensamento [que] volta continuamente ao princípio, regressa com minúcia à própria coisa. Este infatigável movimento de respiração é o modo de ser específico da contemplação" (BENJAMIN, 2011, 17), que observa, em um ritmo intermitente, os vários níveis de sentido de um único objeto.

No tratado não existe uma ambição por uma totalidade sistemática, mas sim uma apreensão fragmentária da coisa, "não receia perder o ímpeto, tal como um mosaico não perde a sua majestade pelo fato de ser caprichosamente fragmentado" (Ibidem). Assim, a apresentação, tal como o mosaico, é composta de elementos singulares e diferentes que transmitem com veemência o impacto transcendente da imagem sagrada e da verdade: "O valor dos

Professora Associada de Filosofia e Professora Permanente do Mestrado Acadêmico em Serviço Social - Universidade Estadual do Ceará (UECE); doutoranda em Filosofia Universidade Federal de Goiás (UFG). Brasileira, residente em Fortaleza-CE. Email: 
fragmentos de pensamento é tanto mais decisivo quanto menos imediata é a sua relação com a concepção de fundo, e desse valor depende o fulgor da apresentação, na mesma medida em que o do mosaico depende da qualidade da pasta do vidro" (Ibidem). Dessa forma, é possível afirmar, com Benjamin, que essa relação inseparável entre a percepção fragmentária e o todo "demonstra que o conteúdo de verdade (Wahrheitsgehalt) se deixa apreender apenas através da mais exata descida ao nível dos pormenores de um conteúdo material (Sachgehalt)" (Ibidem).

Em um contexto filosófico tradicional sistemático e totalizante, uma das grandes dificuldades de entender a apresentação e sua forma de ser fragmentária é que "ela é, por natureza, uma forma de prosa" (BENJAMIN, 1984, 51), que tal como na escrita "é preciso, com cada sentença, parar e recomeçar. A apresentação contemplativa é semelhante à escrita" (Ibidem). Dessa forma, Benjamin assevera que a sobriedade prosaica da apresentação, "desvinculada do preceito doutrinário imperativo, é o único estilo de escrever digno da investigação filosófica" (Ibidem). O objeto de investigação filosófica são as ideias e a apresentação, como método do tratado filosófico, deve ser a apresentação de ideias.

As ideias, diversamente do conhecimento tradicional, têm uma relação diferenciada com a verdade, buscam deixa-la florescer como apresentação do próprio objeto e não como algo "inerente a uma estrutura da consciência, como é o caso da metodologia do saber, mas a um Ser" (BENJAMIN, 1984, 52). A tradição epistemológica, ao contrário, projeta a verdade sobre o objeto a ser conhecido e dele se apossa como conhecimento acabado. Contudo, o conceito a priori imposto ao objeto não coincide com a verdade do objeto. Inversamente, a prática da apresentação, própria ao tratado, busca fazer emergir essa verdade do próprio objeto: "Assim, a distinção entre a verdade e o âmbito do conhecimento define a ideia como ser. É este o alcance da doutrina das ideias para o conceito de verdade" (BENJAMIN, 2011, 18).

Para Benjamin, houve um declínio dos grandes sistemas filosóficos que representam o mundo a partir da ordem das ideias, apesar da sua validade como "esboços de uma descrição do mundo" (Platão, Leibniz e Hegel). Nesses

Professora Associada de Filosofia e Professora Permanente do Mestrado Acadêmico em Serviço Social - Universidade Estadual do Ceará (UECE); doutoranda em Filosofia Universidade Federal de Goiás (UFG). Brasileira, residente em Fortaleza-CE. Email: 
sistemas, a predominância das ideias sobre o mundo empírico fez com que o mundo da empiria fosse absorvido pelas ideias e se dissolvesse nelas. Assim, o filósofo da metodologia da apresentação do tratado buscaria preservar a legitimidade singular da empiria e conservar a idealidade como expressão do mundo empírico, algo inédito na filosofia tradicional que é dedutiva, linear, sistemática e universalista:

Nunca a preocupação com a apresentação parece ter sido contemplada na tarefa do filósofo. O conceito de estilo filosófico está livre de paradoxos. Tem os postulados, que são: a arte da interrupção, contra a cadeia da dedução; o caráter extensivo do tratado, por contraste com o gesto do fragmento; a repetição dos motivos, em contraste com o universalismo raso; a plenitude da positividade concentrada, em contraste com a negação polêmica (BENJAMIN, 2011, 20).

Todavia, os fenômenos empíricos não são assimilados de forma integral pelas ideias, essa divisão entre eles e as ideias é mediada pelo conceito. As ideias salvam os fenômenos nos seus elementos básicos como uma mistura de aparência e empiria, mas essa falsa unidade só é desfeita quando se subordina aos conceitos e, assim, os fenômenos são salvos nas ideias:

\begin{abstract}
O papel mediador dos conceitos permite que os fenômenos participem do ser das ideias. E é precisamente este papel mediador que os torna adequados à outra tarefa, não menos primordial da filosofia, a da apresentação das ideias. A salvação dos fenômenos por meio das ideias vai de par com a apresentação das ideias por meio da empiria. Pois as ideias não se apresentam em si mesmas, mas apenas e exclusivamente através de uma organização dos elementos coisais no conceito. E fazem-no sob a forma da configuração desses elementos (BENJAMIN, 2011, 22).
\end{abstract}

As ideias formam uma configuração dos extremos dos elementos que a fortalecem. Contudo, os fenômenos não estão nas ideias, mas é através da apresentação que elas os alcançam. Analogamente, é possível afirmar que: "As ideias relacionam-se com as coisas como as constelações com as estrelas" (Ibidem). Ou seja, as ideias não são nem os conceitos nem as coisas e não ajudam no conhecimento dos fenômenos que, por sua vez, não são critério para a existência delas, pois à elas só interessam os elementos conceituais dos fenômenos, os quais determinam o alcance e o conteúdo dos conceitos que os circundam. Assim, "as ideias são constelações eternas", nas quais os

Professora Associada de Filosofia e Professora Permanente do Mestrado Acadêmico em Serviço Social - Universidade Estadual do Ceará (UECE); doutoranda em Filosofia Universidade Federal de Goiás (UFG). Brasileira, residente em Fortaleza-CE. Email: 
fenômenos estão "simultaneamente dispersos e salvos" (Ibidem). Os conceitos, por sua vez, agrupam os fenômenos e os fragmentam para alcançar o duplo objetivo da salvação dos fenômenos e da apresentação das ideias (Cf. BENJAMIN, 2011, 23).

Por isso, afirma Benjamin, só é possível pensar que a origem (Ursprung) não tem nada em comum com a gênese (Entstehung), pois “'origem' não designa o processo de devir de algo que nasceu, mas antes aquilo que emerge do processo de devir e desaparecer. A origem insere-se no fluxo do devir como um redemoinho que arrasta no seu movimento o material produzido no processo de gênese." (2011, 34).

Assim, a categoria da origem não é puramente lógica, mas histórica. É próprio da origem (Ursprung) nunca se revelar somente a partir do plano puramente fatual, bem como ela nunca se dá a perceber por inteiro e completamente, pois seu ritmo é de restauração e reconstituição, e sempre incompleto e inacabado. No fenômeno originário, a ideia se confronta, permanentemente, com o mundo histórico e aí atinge sua completude, "a origem, portanto, não se destaca dos dados fatuais, mas tem a ver com a sua pré e pós-história" (Ibidem). Portanto, para Benjamin, na dialética inerente à origem está a observação filosófica como linha mestra e a unicidade e a repetição como movimento, ficando descartado, assim, a remissão a uma gênese primordial.

Dessa forma, é possível afirmar que Benjamin pensa a história filosófica enquanto ciência da origem, ou seja, como uma forma de extremos remotos que aparentemente se apresentam como resultado de excessos da evolução, mas que é, na verdade, uma configuração da ideia como totalidade na qual aqueles opostos coexistem em constelação, indicando a ausência de hierarquia entre eles (Cf. Benjamin, 2011, 35). E isso porque também, na perspectiva metodológica benjaminiana, a formação de conceitos filosóficos não pode somente constatar o devir dos fenômenos no seu ser, "pois o conceito de ser da ciência filosófica não se satisfaz com o fenômeno, precisa de absorver toda a sua história" (Idem, 36). Então, o aprofundamento dessa perspectiva histórica não se limita nem ao passado e nem ao futuro, pois busca dá à ideia a sua

Professora Associada de Filosofia e Professora Permanente do Mestrado Acadêmico em Serviço Social - Universidade Estadual do Ceará (UECE); doutoranda em Filosofia Universidade Federal de Goiás (UFG). Brasileira, residente em Fortaleza-CE. Email: 
dimensão monadológica de totalidade, na qual a ideia enquanto mônada apresenta uma imagem abreviada do mundo:

\begin{abstract}
A sua estrutura, marcada pela totalidade, em contraste com o seu inalienável isolamento, é monadológica. A ideia é uma mônada. O ser que nela penetra com a sua pré e pós-história mostra, oculta na sua própria, a figura abreviada e ensombrada do restante do mundo das ideias, tal como nas mônadas do Discurso sobre a metafísica, de 1686: em cada uma delas estão indistintamente presentes todas as demais. A ideia é uma mônada - nela repousa, preestabelecida, a apresentação dos fenômenos como sua interpretação objetiva (Ibidem).
\end{abstract}

No entanto, é preciso observar que o ser das ideias não pode ser pensado como objeto de uma intuição, nem mesmo uma intuição intelectual (Cf. BENJAMIN, 2011, 23), e nem a verdade é feita de intenção. Ao contrário, "a verdade é a morte da intenção", por isso nunca se tem a posse da verdade (Idem, 24). Contudo, é possível afirmar que mesmo "o ser da verdade, sendo da ordem das ideias, [ele] distingue-se do modo de ser próprio dos fenômenos" (Ibidem). Isto acontece porque mesmo que a verdade não seja intencional e se aproxime da empiria, ela lhe é superior, pois encontra sua força na "própria essência dessa empiria. O ser livre de toda fenomenalidade, e único detentor dessa força, é o ser do nome" (Ibidem).

Ou seja, as ideias não são dadas no mundo dos fenômenos, mas pela palavra, pelo nome. É o nome que determina a forma como as ideias são dadas, por intermédio não de uma "língua primordial, mas antes numa percepção primordial em que as palavras ainda não perderam a aura da sua capacidade de nomear em favor de um significado cognitivo" (Ibidem). Ou seja, a ideia é da ordem da linguagem, assevera Benjamin, na essência da palavra que é símbolo.

Mesmo que as palavras se decomponham na percepção empírica, elas continuam com seu significado profano, paralelo ao simbólico. É o filósofo quem deve restituir, pela apresentação, o caráter primordial da linguagem, oposto ao caráter meramente exterior da comunicação. Naquela restituição, não se trata de revelação, mas de uma rememoração que recupere a percepção primordial da fala (cf. BENJAMIN, 2011, 25). Quanto a isso, afirma Benjamin: 
[...] na contemplação filosófica a ideia enquanto palavra solta-se do recesso mais íntimo da realidade, e essa palavra reclama de novo os seus direitos de nomeação. Mas na origem desta atitude não está, em última análise, Platão, mas Adão, o pai dos homens no papel de pai da filosofia. $O$ ato adâmico da nomeação está tão longe de ser jogo e arbitrariedade que nele se confirma o estado paradisíaco por excelência, aquele que ainda não tinha de lutar com o significado comunicativo das palavras. $\mathrm{Na}$ nomeação, as ideias dão-se destituídas de intenção, a contemplação filosófica é o lugar da sua renovação. Nesta renovação reconstitui-se a percepção original das palavras. (Ibidem).

Dessa forma, diante da Doutrina das ideias, da apresentação, da valorização do estilo de prosa do tratado e do desvio como caminhar metodológico, fica mais clara a recusa benjaminiana de um método dedutivo que se articularia a partir de uma sequência lógica de ideias ou de uma evolução dedutiva de ideias. Nesse sentido, haveria a impossibilidade de uma evolução dedutiva de ideias que remetesse a uma origem como gênese, ou seja, a substância de uma ideia que se apresentaria de forma puramente lógica. Quanto a isso, afirma Benjamin: "Essa impossibilidade é comparável à profunda respiração do pensamento, que depois de tomar fôlego se pode perder, sem pressas e sem o mínimo sinal de inibição, no exame minucioso dos pormenores" (Idem, 33). Isto é possível porque a verdadeira contemplação rejeita o método dedutivo para que não se perca a singularidade dos objetos e dos fenômenos que se expressa por intermédio da apresentação das ideias.

\section{Metodologia e Política: um mosaico de História e Conhecimento}

Damião $(2006,67)$ traduz, com acerto, os elementos mais gerais da permanência de algumas categorias metodológico-epistemológicas do prólogo do livro sobre o drama trágico alemão nas Teses sobre o conceito da história:

A teoria estética se relaciona com a história e o próprio conhecer em
consequência da negação da totalidade e da procura por modos
distintos de percepção que visam romper com a pretensão de
verdade absoluta, com a divisão sujeito-objeto, com o raciocínio
puramente dedutivo e a ideia de sistema.

De imediato, salta aos olhos, na confluência desses dois textos, o exercício metodológico da apresentação na formulação das teses sobre o conceito de historia. Assim, é possível observar que o texto não tem um caráter

Professora Associada de Filosofia e Professora Permanente do Mestrado Acadêmico em Serviço Social - Universidade Estadual do Ceará (UECE); doutoranda em Filosofia Universidade Federal de Goiás (UFG). Brasileira, residente em Fortaleza-CE. Email: 
sistemático, dedutivo ou universalizante. Apesar de não se estruturar nos moldes de um tratado, o conjunto das teses foge àquela formulação fechada da filosofia tradicional. Da mesma forma, é possível observar que a proposta metodológica do caminho indireto, do desvio, também está presente, na medida em que Benjamin não se propõe a desvelar de forma linear e objetiva o conceito de história, nem muito menos sua representação epistemológica.

Seguindo o ritmo intermitente da apresentação, Benjamin volta continuamente ao conceito de história, em um "infatigável movimento de respiração [que] é o modo de ser específico da contemplação", perseguindo, assim, os vários níveis de sentido que tem a história, mas nunca querendo alcançar uma totalidade sistemática do conceito. Ao contrário, vai construindo um mosaico do conceito de história com os fragmentos das teses, as quais funcionam como as ideias da apresentação, em um estilo de prosa que se firma na explicitação do objeto (Ser) história, ao invés de impor uma verdade pré-estabelecida, retirada de alguma metodologia apriorística do saber.

É possível observar essa recusa de um conhecimento linear e acabado, dentre outras passagens, no inicio da VI tese: "Articular o passado historicamente não significa conhecê-lo 'tal como ele propriamente foi'. Significa apropriar-se de uma lembrança tal como ela lampeja num instante de perigo". Segundo Löwy (2005), Benjamin rejeita nessa passagem a concepção historicista/positivista que defende uma neutralidade no conhecimento da história que existiria nos fatos reais.

Assim, metodologicamente, Benjamin segue a interrupção no lugar da dedução, um pensar descontinuado no lugar de um pensamento pronto que se impõe. Ou seja, não oferece uma cadeia dedutiva conceitual abstrata sobre a história, mas sim persegue a história nos seus movimentos políticos e econômicos reais. Da mesma maneira, se afasta da universalidade abstrata, sem cair, contudo, em um empirismo grosseiro, pois os fenômenos são salvos nas ideias. Na tese XIII é possível vislumbrarmos com mais clareza a recusa de uma concepção universalista de história presente na ideia de progresso da teoria socialdemocrata, a qual defendia, segundo Benjamin, "um conceito de progresso que não se orientava pela realidade, mas que tinha uma pretensão

Professora Associada de Filosofia e Professora Permanente do Mestrado Acadêmico em Serviço Social - Universidade Estadual do Ceará (UECE); doutoranda em Filosofia Universidade Federal de Goiás (UFG). Brasileira, residente em Fortaleza-CE. Email: 
dogmática": era um progresso da própria humanidade; um progresso interminável da perfectibilidade infinita da humanidade; e um progresso essencialmente irresistível, percorrendo autonomamente uma trajetória reta ou em espiral. Benjamin fecha essa tese chamando atenção para a necessidade da crítica a esses pressupostos universais e abstratos da história: "A representação de um progresso do gênero humano na história é inseparável da representação do avanço dessa história percorrendo um tempo homogêneo e vazio. A crítica à representação desse avanço tem de ser a base crítica da representação do progresso em geral".

Löwy (2005, 116), comentando essa tese e explicitando a crítica benjaminiana, enfatiza a mediocridade e limitação do "progressismo" socialdemocrata que estava intimamente inspirado na "visão otimista linear da história, alimentada por uma leitura superficial da Aufklärung", o qual proclamava um desenvolvimento irresistível e ininterrupto da clareza e inteligência humanas. No entanto, essa abstração universalizante foi desmentida pela realidade trágica do fascismo. Assim, no pensamento benjaminiano, não há um progresso 'automático' ou 'contínuo'. A única continuidade é a da dominação que se reproduz na história quase que automaticamente como regra. As exceções nessa continuidade são os momentos de liberdade que se configuram como interrupções, descontinuidades dos oprimidos ao se sublevarem em busca de emancipação.

A origem (Ursprung), que não se confunde com a gênese (Entstehung), possibilita pensar a história fora de uma linearidade progressiva e lógica e compreender que passado e presente estão interligados, no sentido que o passado está no presente e o presente está no passado. Constituem extremos opostos que coexistem em constelação, não havendo um momento inicial de uma gênese primeira. Diz Benjamin no inicio da tese $\mathrm{V}$ :

\footnotetext{
A verdadeira imagem do passado passa célere e furtiva. E somente como imagem que lampeja justamente no instante da recognoscibilidade, para nunca mais ser vista, que o passado tem de ser capturado. [...]. Pois é uma imagem irresistível do passado que ameaça desaparecer com cada presente que não se reconhece como nela visado.
} 
Nessa passagem da tese $\mathrm{V}$, fica exposta a contraposição entre a postura do historiador tradicional e do historiador adepto do materialismo histórico que, segundo Löwy, tem por objetivo "descobrir a constelação crítica que um fragmento do passado forma precisamente com um momento do presente. A dimensão política e ativa dessa relação com o passado [...]" (2005, 62). Daí na importância da rememoração que, por sua vez, também implica a importância da redenção. Assim, "não convém perder de vista que a 'intervenção salvadora' tem por objeto tanto o passado quanto o presente: história e política, rememoração e redenção são inseparáveis" (Idem). Contudo, esses objetos históricos, por sua vez, constituem mônadas, pois cada época traz em si todas as outras, mas sem configurar uma relação de causa e efeito, próprio do historicismo positivista.

Assim, por esses "descaminhos" metodológicos, a apresentação possibilita pela linguagem, expressão maior das ideias, a rememoração, pela qual o tempo passado é revivido e não se deixa ser esquecido. O que pode possibilitar a vinda do Messias (Revolução):

A ultima classe que luta contra a opressão e que é encarregada,
segundo Marx, da "obra de libertação" - o proletariado - não pode
realizar esse papel, segundo Benjamin, se esquecer seus ancestrais
martirizados: não há luta pelo futuro sem memória do passado. Trata-
se do tema da redenção das vítimas da história, que já encontramos
nas teses II, III e IV, em seu duplo alcance, teológico e político
(LÖWY, 2005, 109).

Para Geraldo (1992, 93), a ideia de "redenção" está inscrita na Filosofia da História de Benjamin como "proposta de salvação dos fenômenos, objetos da história, enquanto fragmentos da história, através da imersão nos mesmos, o que pressupõe uma paralisação e explosão do continuum que os aprisiona". Ou seja, é uma compreensão não linear da história, baseada na descontinuidade e não em uma sucessão linear de etapas. A contestação mais significativa aí é feita também à visão hegeliana idealista da história, que defendia a história como um desenvolvimento progressivo em direção à realização do espirito absoluto. Essa concepção historicista acabaria por fazer valer somente a história dos vencedores. Ou seja, a história contínua, linear e progressiva tende a registrar somente o movimento dos vencedores, com quem 
o "historiador do historicismo se identifica afetivamente", como dito na tese VII (Benjamin, 2005).

Essa dimensão política é fundamental para a compreensão das teses benjaminianas sobre a história que, ao afirmar uma descontinuidade da história estaria também afirmando a necessidade de fazer valer a força dos vencidos mediante o poder dos vencedores. Haveria, portanto, uma conexão metodológica e politica na forma de ver a história proposta nas teses. A tese VII expressa claramente esse ponto:

\begin{abstract}
Ora, os dominantes de turno são os herdeiros de todos os que, algum dia, venceram. A identificação afetiva com o vencedor ocorre, portanto, sempre, em proveito dos vencedores de turno. Isso diz o suficiente para o materialismo histórico. Todo aquele que, até hoje, obteve a vitória, marcha junto no cortejo de triunfo que conduz os dominantes de hoje [a marcharem] por cima dos que, hoje, jazem por terra. A presa, como sempre de costume, é conduzida no cortejo triunfante.
\end{abstract}

Portanto, é possível afirmar que a proposta metodológico-epistemológica utilizada nas teses tem uma implicação política e ética. Como diz Cantinho: "A visão benjaminiana da história é um projeto eminentemente ético/prático" $(2015,49)$. Da mesma forma, Callado (2006) corrobora essa relação entre a metodologia e a política: "Com o objetivo crítico de questionar a realidade com vistas à mudança, a tese sete de 'Sobre o Conceito de História' propõe escovar a História a contrapelo (die Geschichte gegen den Strich zu bürsten)" (p. 85). Com o objetivo de reformular a Filosofia da História, a tese recusa o historicismo da história universal em favor da historiografia materialista.

Assim, para tirar as reivindicações e transformações politicas do conformismo se faz necessária a reflexão: "Essa forma de agir politicamente se inicia com o método que distingue o particular a sua especificidade e por isso não se enquadrou na média do sistema e foi reprovado justamente pelo desejo de participar com sua ação particular" (Callado, 2006, 98). Ou seja, o método benjaminiano, ao valorizar e reconhecer o particular, dispensando o universal que exclui o singular, possibilita a reconciliação dos singulares também na totalidade da experiência, e não somente no nível epistêmico.

Löwy $(2005,118)$ também se expressa sobre essa relação metodológico-epistemológica com a política: "O que está em jogo no debate

Professora Associada de Filosofia e Professora Permanente do Mestrado Acadêmico em Serviço Social - Universidade Estadual do Ceará (UECE); doutoranda em Filosofia Universidade Federal de Goiás (UFG). Brasileira, residente em Fortaleza-CE. Email: 
está longe de ser puramente teórico e filosófico. Trata-se, salienta Benjamin, de uma certa atitude prática, que combina o otimismo do progresso com a ausência de iniciativa, a passividade, o imobilismo". Esse conformismo da esquerda alemã à época, ainda segundo as análises de Löwy, encontrou seu desfecho trágico na capitulação sem combate da esquerda alemã diante de Hitler em 1933 e da esquerda francesa em 1940.

Segundo Gagnebin (1999, 96), Benjamin "mesmo quando fala de revolução (ou em Revolução), recusa a ideia de um processo cumulativo e progressivo que levaria a uma forma secularizada de redenção. Nem por isso defende um espontaneísmo ou um anarquismo ingênuo". Muito pelo contrário, critica o imediatismo dessas posições e "insiste na necessidade de uma 'armação teórica' que sustente a escrita da história e a prática política” (Idem).

Ou seja, a modificação teórica deve visar também a uma modificação da prática política que leve a uma preocupação com o presente histórico e político. Assim, Benjamin afirma, no apêndice 1 das Teses, que a historiografia com a ideia de progresso e o historicismo com a noção de tempo linear se contentam "em estabelecer um nexo causal entre os diversos momentos da história. Mas nenhum fato, por ser causa, já é, só por isso, um fato histórico". À essa linearidade do tempo, Benjamin se contrapõe com o "conceito pleno de 'tempo de agora' (Jetztzeit), ao mesmo tempo surgimento (Ursprung) do passado no presente e 'evento do instante, daquilo que começa a ser... que deve, pelo seu começo, nascer de si, advir a si, sem partir de lugar nenhum"' (Idem, 97).

A percepção metodológica da descontinuidade, presente no livro do drama barroco alemão, queria fazer valer, num exercício também político, a realidade singular de um gênero literário desprezado pelos estudos tradicionais e o apresentar como ideia que fizesse vir à tona e explodir o autoritarismo da historiografia literária linear e oficial dos grandes gêneros classificáveis em grandes escolas. Essa ousadia também está presente nas teses, bem como a sua proximidade com a política. Assim, "Benjamin tenta pensar uma "tradição" dos oprimidos que não repousaria sobre o nivelamento da continuidade, mas sobre os saltos, o surgimento (Ur-sprung), a interrupção e o descontínuo" (GAGNEBIN, 1999, 99). No pensamento benjaminiano a história contínua é a

Professora Associada de Filosofia e Professora Permanente do Mestrado Acadêmico em Serviço Social - Universidade Estadual do Ceará (UECE); doutoranda em Filosofia Universidade Federal de Goiás (UFG). Brasileira, residente em Fortaleza-CE. Email: 
história dos opressores, pois a representação do continuum iguala tudo; já a apresentação do descontínuo expressaria uma autêntica tradição que é a dos oprimidos.

Gagnebin (1999) reconhece que no contexto altamente político das teses, há uma conexão estreita entre interrupção e revolução, que em nossas palavras estamos nos referindo como metodologia e política. E esta estudiosa de Benjamin ainda assevera, fazendo valer a nossa afirmação entre os estreitos laços entre epistemologia e política: "[...] o que a história tradicional quer apagar são os buracos da narrativa que indicam tantas brechas possíveis no continuum da dominação" (Idem, 100).

\section{Conclusão}

É possível concluir, então, que apesar da distância que separa os dois textos aqui trabalhados (Origem do drama trágico alemão, 1924; Sobre o conceito da História, 1940), em ambos estão presentes conceitos em comum. Como exposto na Introdução, a permanência de alguns conceitos nestes textos diferentes caracteriza, no entanto, o que estamos chamando aqui de permanência ampliada, já que se trata do uso de conceitos para pensar outras realidades que não as iniciais de onde brotaram aqueles conceitos.

Assim, foi possível observar a retomada do exercício metodológico da apresentação como método para a elaboração das Teses sobre a História, bem como vários conceitos de sua constelação categorial. Outro importante aspecto que ficou evidenciado presente em ambos os textos foi a relação entre metodologia e política, comprovando que a preocupação epistemológica benjaminiana não se circunscreve a uma mera preocupação epistêmica.

\section{REFERÊNCIAS}

\footnotetext{
Professora Associada de Filosofia e Professora Permanente do Mestrado Acadêmico em Serviço Social - Universidade Estadual do Ceará (UECE); doutoranda em Filosofia Universidade Federal de Goiás (UFG). Brasileira, residente em Fortaleza-CE. Email: cmarinho2004@gmail.com
} 
BENJAMIN, Walter. Origem do drama trágico alemão; edição e tradução João Barrento. Belo Horizonte: Autêntica Editora, 2011.

Origem do drama barroco alemão; tradução,

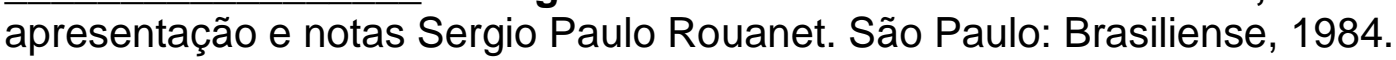

Sobre o conceito da História. In Magia e técnica, arte e política: ensaios sobre literatura e história da cultura; $7 \stackrel{\text { a }}{\text { ed.; tradução }}$ Sérgio Paulo Rouanet; prefácio Jeanne Marie Gagnebin. São Paulo: Brasiliense, 1994. (obras escolhidas; v.1).

Sobre o conceito da História. In_ : Walter Benjamin: o anjo da História. Edição e tradução de João Barrento. Lisboa: Assírio \& Alvim, 2008. (Obras escolhidas de Walter Benjamin; v.4).

Sobre o conceito da História. In__: LÖWY, Michael. Walter Benjamin: aviso de incêndio: uma leitura das teses "Sobre o conceito de história". Tradução de Wanda Nogueira Caldeira Brant, [tradução das teses] Jeanne Marie Gagnebin, Marcos Lutz Müller. São Paulo: Boitempo, 2005.

CALLADO, Tereza de Castro. Walter Benjamin e a experiência da origem; prefácio de Olgária Matos. Fortaleza: EdUECE, 2006. (Coleção Argentum Nostrum).

CANTINHO, Maria João. O Anjo Melancólico: Ensaio sobre o conceito de alegoria na obra de Walter Benjamin. $2^{\underline{a}}$ ed. Paris: Nota de Rodapé Edições, 2015.

DAMIÃO, Carla Milani. Sobre o declínio da "sinceridade": Filosofia e autobiografia de Jean-Jacques Rousseau a Walter Benjamin. São Paulo: Edições Loyola, 2006.

GAGNEBIN, Jeanne-Marie. Do conceito de Darstellung em Walter Benjamin ou verdade e beleza. In_: KRITERION. Belo Horizonte, no 112, Dez/2005, p. 183190. Disponível em:

http://www.scielo.br/scielo.php?script=sci arttext\&pid=S0100-

$\underline{512 \times 2005000200004}$

História e narração em Walter Benjamin. $2^{\mathrm{a}}$ ed.

São Paulo: Editora perspectiva, 1999. (Coleção Estudos).

GERALDO, Sheila Cabo. "Origem do Drama Barroco Alemão": leitura e tentativa de compreensão das noções de Origem, Redenção, Mônada, Alegoria, Melancolia e Linguagem. In__: 0 que nos faz pensar, no 6, Agosto de 1992. Disponível em: 
http://www.oquenosfazpensar.com/adm/uploads/artigo/origem do drama alem ao: leitura e tentativa de compreensao das nocoes da origem, redencao, monada, alegoria, melancolia e linguagem/n6sheila.pdf

LÖWY, Michael. Walter Benjamin: aviso de incêndio: uma leitura das teses "Sobre o conceito de história". Tradução de Wanda Nogueira Caldeira Brant, [tradução das teses] Jeanne Marie Gagnebin, Marcos Lutz Müller. São Paulo: Boitempo, 2005.

ROUANET, Sergio Paulo. Édipo e o anjo: itinerários freudianos em Walter Benjamin. $2^{\underline{a}}$ ed. Rio de Janeiro: Edições Tempo Brasileiro, 1990. (Biblioteca Tempo Universitário, 63).

SELIGMANN-SILVA, Marcio. Walter Benjamin: o Estado de Exceção entre o político e o estético. outra travessia, Florianópolis, n. 5, p. 25-38, jan. 2005. ISSN 2176-8552. Disponível em:

$<$ https://periodicos.ufsc.br/index.php/Outra/article/view/12579/11746>. Acesso em: 10 jan. 2017. doi:http://dx.doi.org/10.5007/12579. 